\title{
Blood eosinophil count and risk of pneumonia hospitalisations in individuals with COPD
}

\author{
Signe Vedel-Krogh ${ }^{1,2}$, Børge G. Nordestgaard ${ }^{1,2,3}$, Peter Lange $e^{2,4,5}$, \\ Jørgen Vestbo ${ }^{6,7}$ and Sune F. Nielsen ${ }^{1,2}$
}

Affiliations: ${ }^{1}$ Dept of Clinical Biochemistry, Herlev and Gentofte Hospital, Copenhagen University Hospital, Copenhagen, Denmark. ${ }^{2} T$ The Copenhagen General Population Study, Herlev and Gentofte Hospital, Copenhagen University Hospital, Copenhagen, Denmark. ${ }^{3}$ Faculty of Health and Medical Sciences, University of Copenhagen, Copenhagen, Denmark. "Dept of Public Health, Section of Social Medicine, University of Copenhagen, Copenhagen, Denmark. ${ }^{5}$ Medical Dept, Respiratory Section, Herlev and Gentofte Hospital, Copenhagen University Hospital, Copenhagen, Denmark. ${ }^{6}$ Division of Infection Immunity and Respiratory Medicine, School of Biological Sciences, The University of Manchester, Manchester, UK. ${ }^{7}$ University Hospital South Manchester NHS Foundation Trust, Manchester Academic Health Science Centre, Manchester, UK.

Correspondence: Sune F. Nielsen, Dept of Clinical Biochemistry, 54M1, Herlev and Gentofte Hospital, Copenhagen University Hospital, Herlev Ringvej 75, DK-2730 Herlev, Denmark.

E-mail: sune.fallgaard.nielsendregionh.dk

\section{@ERSpublications}

Eosinophilic COPD with severely impaired lung function is associated with high risk of pneumonia hospitalisations http://ow.ly/Tyl130jsi1D

Cite this article as: Vedel-Krogh S, Nordestgaard BG, Lange P, et al. Blood eosinophil count and risk of pneumonia hospitalisations in individuals with COPD. Eur Respir J 2018; 51: 1800120 [https://doi.org/ 10.1183/13993003.00120-2018].

ABSTRACT Blood eosinophil count in chronic obstructive pulmonary disease (COPD) is associated with higher exacerbation rate and favourable response to corticosteroids; however, frequent exacerbations and use of inhaled corticosteroids could elevate pneumonia risk. We tested the hypothesis that high blood eosinophil counts are associated with high risk of pneumonia in individuals with severe COPD from the general population.

We included 7180 individuals with COPD from the Copenhagen General Population Study, including 643 with forced expiratory volume in $1 \mathrm{~s}\left(\mathrm{FEV}_{1}\right)<50 \%$ predicted between 2003 and 2011. All primary discharge diagnoses of pneumonia during follow-up were recorded.

Among individuals with $\mathrm{COPD}$ and $\mathrm{FEV}_{1}<50 \%$ pred, the multivariable adjusted incidence rate ratio was 2.17 (95\% CI 1.31-3.58) for pneumonia comparing individuals with blood eosinophil counts $\geqslant 0.34 \times 10^{9}$ cells $\cdot \mathrm{L}^{-1}$ versus $<0.34 \times 10^{9}$ cells $\cdot \mathrm{L}^{-1}$. In individuals with clinical COPD, defined by recent exacerbation, $\geqslant 10$ pack-years of smoking and FEV1 $<70 \%$ pred, the corresponding risk was 4.52 (2.119.72). Risk of pneumonia did not differ by blood eosinophil count in individuals with COPD and FEV1 $\geqslant 50 \%$ pred.

In individuals with COPD and FEV $1<50 \%$ pred, blood eosinophil count $\geqslant 0.34 \times 10^{9}$ cells $\cdot \mathrm{L}^{-1}$ was associated with high risk of hospitalisation due to pneumonia. 


\section{Introduction}

The risk of pneumonia is elevated in individuals with chronic obstructive pulmonary disease (COPD) [1, 2]; and high age, comorbidity, a history of exacerbations and severe disease with reduced forced expiratory volume in $1 \mathrm{~s}(\mathrm{FEV} 1)$ have all been identified as risk factors for the development of pneumonia in COPD $[2,3]$. Furthermore, therapy with inhaled corticosteroids (ICS) in COPD is associated with an elevated risk of pneumonia [4-6] and possibly excess pneumonia deaths [7]. Retrospective analyses have not reported a difference in pneumonia incidence according to the levels of blood eosinophils in patients with COPD [8], but a recent post hoc meta-analysis of clinical trials found that COPD patients with blood eosinophil counts $<2 \%$ had more pneumonia events compared to patients with higher blood eosinophil counts [9]. In addition, some studies suggest that there may exist an inverse relationship between sputum eosinophil count and sputum bacterial count [10].

The peripheral blood eosinophil counts correlate with sputum eosinophil counts in patients with COPD, and thus blood eosinophil count is emerging as a biomarker of eosinophilic airway inflammation [11, 12]. Although reports of higher readmission rates in COPD patients with increased blood eosinophil counts at hospitalisation are conflicting [13,14], previous studies have found that blood eosinophil counts are associated with future risk of exacerbations. Using a cut-point for eosinophils of $\geqslant 2 \%$ of total blood leukocytes or a cut-point in absolute number of $0.34 \times 10^{9}$ cells $\cdot \mathrm{L}^{-1}$, these studies suggest that an elevated blood eosinophil count is associated with a higher risk of COPD exacerbations $[8,15,16]$.

Although controversial [17], high blood eosinophil counts in COPD probably marks a phenotype associated with frequent exacerbations, which could influence the risk of pneumonias, and we speculated that high blood eosinophil counts may mark high risk of pneumonia in individuals with COPD. As pneumonias leading to hospitalisation are rare in mild to moderate COPD, we tested the hypothesis that a blood eosinophil count of $\geqslant 0.34 \times 10^{9}$ cells $\mathrm{L}^{-1}$ in individuals with COPD ranging in severity as assessed by FEV1 \% predicted was associated with high risk of being hospitalised due to pneumonia. Furthermore, using the same cut-point in blood eosinophils, in addition we tested whether a high blood eosinophil count was associated with high risk of pneumonias in individuals with clinical exacerbating COPD [16] defined by recent exacerbation, $\geqslant 10$ pack-years and $\mathrm{FEV}_{1}<70 \%$ pred. For this purpose, we studied individuals with COPD from the Copenhagen General Population Study (CGPS), all with baseline measurements of blood eosinophil counts, and followed these up to 8 years for development of pneumonia in a prospective study design.

\section{Methods}

\section{Copenhagen General Population Study}

The CGPS is a prospective study of the general population residing in Greater Copenhagen [18-20] with ongoing recruitment begun in 2003. All participants performed spirometry and we defined COPD as a ratio of $\mathrm{FEV}$ //forced vital capacity $(\mathrm{FVC})<0.7$ and less than the lower limit of normal, excluding individuals with self-reported asthma. We further subdivided the COPD population according to Global Initiative for Chronic Obstructive Lung Disease (GOLD) grade 1-2, and GOLD grade 3-4; that is, FEV1 $\geqslant 50 \%$ pred and $<50 \%$ pred. Within the COPD population, we defined a subpopulation with clinical COPD based on the following criteria: at least one exacerbation in the year prior to baseline, $\geqslant 10$ pack-years of smoking and FEV $1<70 \%$ pred, as done previously [16]. From 81107 individuals from the CGPS, we identified 7180 individuals with COPD with full information on spirometry and blood biomarker measurements; of these, 4832 had smoked $>10$ pack-years.

Information on the use of ICS was obtained by linking CGPS to the national Danish Registry of Medicinal Products Statistics, which records all prescriptions dispensed in Danish pharmacies.

\section{Blood eosinophil counts}

Blood eosinophil counts were measured in fresh blood samples using the ADVIA 120 haematology system (Siemens Healthineers, Erlingen, Germany) and reported in total numbers $\left(\times 10^{9}\right.$ cells $\left.\cdot \mathrm{L}^{-1}\right)$. We defined high versus low eosinophil counts in individuals with COPD as blood eosinophil counts of $\geqslant 0.34 \times 10^{9}$ cells $\cdot \mathrm{L}^{-1}$ versus those $<0.34 \times 10^{9}$ cells $\cdot \mathrm{L}^{-1}$, as determined in our previous work on blood eosinophil counts and COPD exacerbations [16]. However, in sensitivity analyses we used blood eosinophil cut-points of $2 \%$ of all leukocytes, which has been widely used [15], and 3.3\%, determined in our previous work [16].

\section{Pneumonia}

Risk of pneumonia was analysed prospectively. We defined pneumonia events as a hospital admission with a primary discharge diagnosis of pneumonia (World Health Organization International Classification of Diseases code J12-J18). Information on diagnoses was drawn from the national Danish Patient Registry, 
which records all hospital contacts in Denmark, and linked to the CGPS. Prior pneumonia events were defined in the same manner as pneumonias during follow-up, but with an admission date before the date of examination in the CGPS.

\section{Statistical analysis}

Analyses were performed using STATA/SE software (version 14.1; StataCorp, College Station, TX, USA).

A negative binomial regression model with $95 \%$ confidence intervals was used to compare risk of pneumonias during follow-up. Analyses were multivariable adjusted for sex, age, smoking status, pack-years of smoking, body mass index, education and $\mathrm{FEV}_{1} \%$ pred. Potential confounders were pre-specified and included, irrespective of their contribution to the model. A nested model with and without blood eosinophil counts was tested using a likelihood ratio test. Additionally, we included use of ICS in the year prior to baseline, and inflammatory biomarkers high sensitivity C-reactive protein, fibrinogen and total leukocytes as confounders, as these have previously been associated with the risk of pneumonia in COPD [21]. Follow-up began at study entry and ended at death $(n=583)$, emigration $(n=8)$ or end of follow-up (December 31, 2011), whichever came first. We tested for interaction of blood eosinophil counts and ICS use and risk of pneumonias using the likelihood-ratio test.

Imputation of missing covariates at baseline for adjustments in the multivariable adjusted analyses was done by multivariable regression. However, analyses only including individuals with full information on covariates gave similar results to those reported.

Additional details on the methods are provided in the online supplementary material.

\section{Results}

We included 7180 individuals with COPD (figure 1). Median follow-up time was 3.7 years (interquartile range (IQR) $1.5-5.8$ years). Among individuals with $\mathrm{COPD}$ and $\mathrm{FEV} 1 \geqslant 50 \%$ pred, 271 were hospitalised

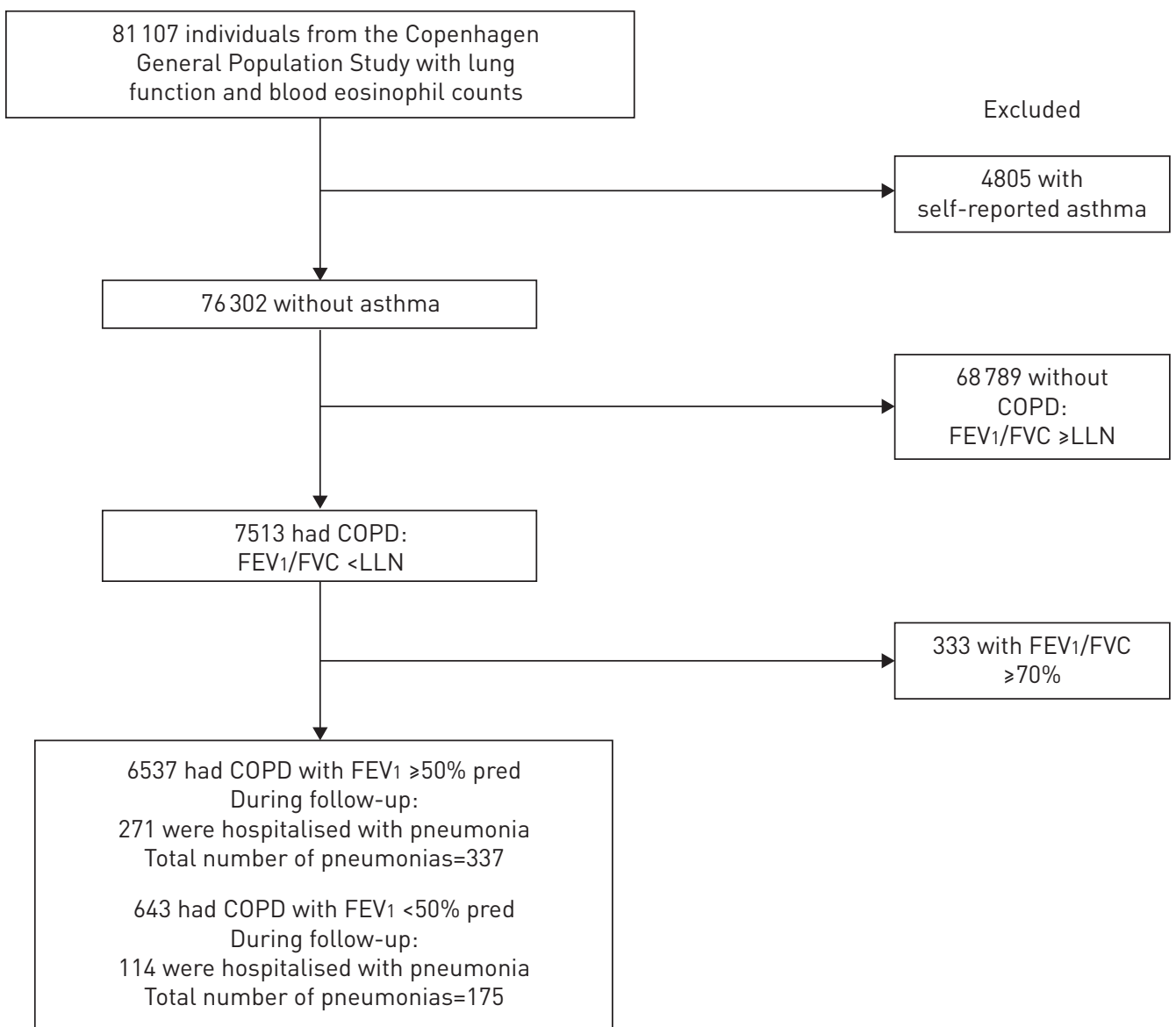

FIGURE 1 Study population. COPD: chronic obstructive pulmonary disease; FEV1: forced expiratory volume in $1 \mathrm{~s} ;$ FVC: forced vital capacity; LLN: lower limit of normal. 
TABLE 1 Baseline characteristics of individuals with chronic obstructive pulmonary disease according to blood eosinophil count and forced expiratory volume in $1 \mathrm{~s}(\mathrm{FEV} 1) \%$ predicted

FEV $1<50 \%$ pred

Blood eosinophils $\begin{gathered}\text { Blood eosinophils } \\ <0.34 \times 10^{9} \text { cells } \mathrm{L}^{-1}\end{gathered} \geqslant 0.34 \times 10^{9}$ cells $\cdot \mathrm{L}^{-1}$

\section{Subjects $\mathbf{n}$}

Male

Age years

Current smokers

Pack-years of smoking ${ }^{\#}$

$\geqslant 10$ pack-years of smoking ${ }^{\#}$

Body mass index $\mathrm{kg} \cdot \mathrm{m}^{-2}$

Low level of education"

FEV $1 \%$ predicted

Users of inhaled

corticosteroids ${ }^{+}$

Ischaemic heart disease

prior to baseline

Frequency of exacerbations

per individual per year

during follow-up

Number of high biomarkers ${ }^{\S}$

0

1

2

3

521
$261(50)$
$71(64-77)$
$224(43)$
$40(26-55)$
$445(85)$
$25.5(22.6-28.5)$
$346(66)$
$42(36-46)$
$148(28)$

$71(14)$

$0.59 \pm 1.28$

$198(38)$
$161(31)$
$118(23)$
$44(8)$

FEV $1 \geqslant 50 \%$ pred

$\begin{array}{cc}\text { Blood eosinophils } & \text { Blood eosinophils } \\ <0.34 \times 10^{9} \text { cells } \cdot L^{-1} & \geqslant 0.34 \times 10^{9} \text { cells } \cdot L^{-1}\end{array}$

5646

5646
$2700(48)$

$63(53-71)$

2045 (36)

$28(15-42)$

$3641(64)$

$24.9(22.7-27.6)$

$2977(53)$

81 (69-91)

$250(4)$

$424(8)$

$0.11 \pm 0.50$

$0.12 \pm 0.45$

$<0.001$

0.01

$<0.001$

$29(24)$
$37(30)$
$31(25)$
$25(21)$

$\begin{array}{cc}3425(61) & 404(45) \\ 1408(25) & 274(31) \\ 610(11) & 145(16) \\ 203(4) & 68(8)\end{array}$

Data are presented as $\mathrm{n}(\%)$, median (interquartile range) or mean \pm SD, unless otherwise stated. $\mathrm{n}=7180$. ${ }^{\#}$ : pack-years were calculated for current and former smokers only; ${ }^{\uparrow}$ : low level of education was $<3$ years following mandatory primary school; ${ }^{+}$: recorded up to 1 year prior to baseline; ${ }^{\S}$ : defined as C-reactive protein $>3 \mathrm{mg} \cdot \mathrm{L}^{-1}$, leukocytes $>9 \times 10^{9}$ cells $\cdot \mathrm{L}^{-1}$ and/or fibrinogen $>14 \mu \mathrm{mol} \cdot \mathrm{L}^{-1}$, as done previously $[18,21]$.

due to pneumonia during follow-up; of these, 51 individuals were hospitalised due to pneumonia more than once. In the COPD population with $\mathrm{FEV}_{1}<50 \%$ pred, 114 were hospitalised due to pneumonia during follow-up; of these, 36 individuals were hospitalised more than once.

Baseline characteristics according to eosinophil count $\geqslant 0.34 \times 10^{9}$ cells $\cdot \mathrm{L}^{-1}$ versus $<0.34 \times 10^{9}$ cells $\cdot \mathrm{L}^{-1}$ in the COPD population divided according to $\mathrm{FEV}_{1} \%$ pred are shown in table 1 . A higher proportion of individuals with COPD and a blood eosinophil count of $\geqslant 0.34 \times 10^{9}$ cells $\cdot \mathrm{L}^{-1}$ had elevated markers of low-grade systemic inflammation regardless of $\mathrm{FEV}_{1} \%$ pred. Among individuals with COPD and FEV 1 $<50 \%$ pred, we found no difference in the percentage of patients treated with ICS according to blood eosinophil count, and the distribution of those treated with fluticasone versus budesonide did not differ significantly (online supplementary table S1).

\section{Blood eosinophil counts and risk of pneumonia}

Among individuals with COPD and $\mathrm{FEV}_{1}<50 \%$ pred, we found a multivariable adjusted incidence rate ratio (95\% CI) of 2.17 (1.31-3.58) for pneumonia comparing individuals with blood eosinophil count of $\geqslant 0.34 \times 10^{9}$ cells $\cdot \mathrm{L}^{-1}$ versus those $<0.34 \times 10^{9}$ cells $\cdot \mathrm{L}^{-1}$ (figure $2 \mathrm{a}$ ). The risk remained significant, although attenuated, with a risk ratio of $1.81(1.11-2.94)$ after further adjustment for the use of ICS, inflammatory biomarkers and prior pneumonia events. Compared to the nested full model without blood eosinophil counts, including eosinophils at a cut-point of $0.34 \times 10^{9}$ cells $\cdot \mathrm{L}^{-1}$ improved the model (likelihood ratio test $\mathrm{p}=0.02$ ). Further adjusting the model for exacerbations in the year prior to baseline gave an incidence rate ratio of 1.80 (1.13-2.86). Among individuals with $\mathrm{COPD}$ and $\mathrm{FEV} 1 \geqslant 50 \%$ pred, the multivariable adjusted incidence rate ratio for pneumonias was $0.80(0.55-1.15)$ and further adjustment for the use of ICS, inflammatory biomarkers and prior pneumonia events did not change the results. Among individuals with COPD and with $\geqslant 10$ pack-years of smoking, repeating these analyses gave similar results (figure $2 b$ ). Furthermore, in a model not taking multiple pneumonias into account, the main findings were similar (online supplementary figure S1). Risk of pneumonia using a multivariable adjusted Cox proportional hazard model excluding individuals with a hospitalisation due to pneumonia before baseline gave similar, although nonsignificant results when comparing individuals with a blood eosinophil count of $\geqslant 0.34 \times 10^{9}$ cells $\cdot \mathrm{L}^{-1}$ to those $<0.34 \times 10^{9} \mathrm{cells} \cdot \mathrm{L}^{-1}$ (online supplementary figure S2). Including only 


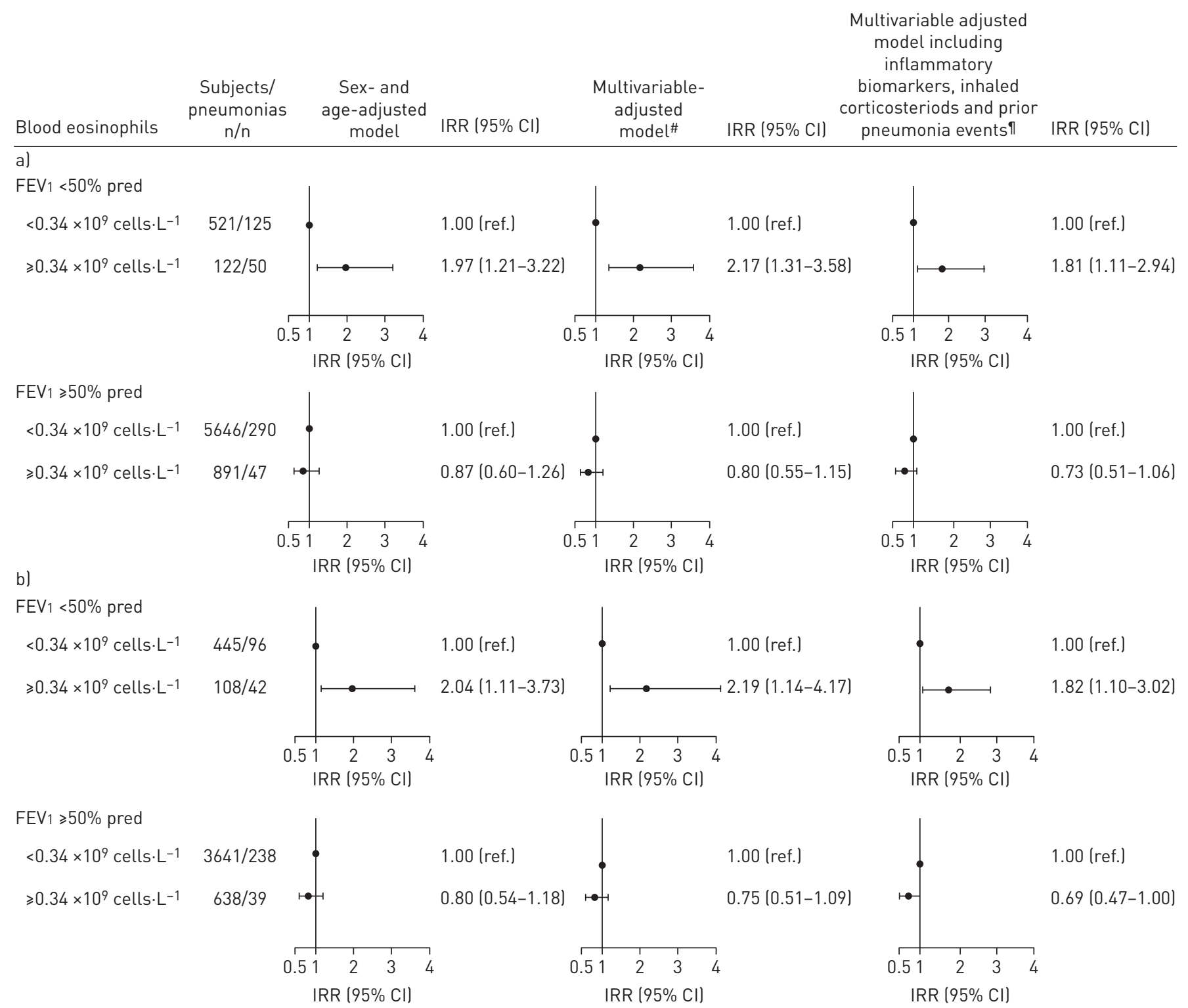

FIGURE 2 Risk of pneumonia in individuals with chronic obstructive pulmonary disease (COPD) according to blood eosinophil count. a) Individuals with COPD were grouped based on their forced expiratory volume in $1 \mathrm{~s}$ (FEV 1 ) \% predicted, according to the Global Initiative for Chronic Obstructive Lung Disease spirometric classification of COPD severity using FEV1 \% pred $(n=7180)$; b) analyses were repeated in a COPD population restricted to $\geqslant 10$ pack-years of smoking ( $n=4832$ ). IRR: incidence rate ratio. \#: adjusted for sex, age, smoking status, pack-years of smoking, body mass index, education and $\mathrm{FEV} 1 \%$ pred; " inflammatory biomarkers were high sensitivity $\mathrm{C}$-reactive protein, leukocyte count and fibrinogen.

individuals with COPD and no use of ICS prior to baseline gave similar, although nonsignificant results (online supplementary figure S3). In both forward and backward stepwise regression models, significant covariates were prior pneumonia events, number of high inflammatory biomarkers and blood eosinophil count (online supplementary table S2).

Using cut-points of $2 \%$ and $3.3 \%$ in blood eosinophils, individuals with FEV1 $<50 \%$ pred and higher percentages of blood eosinophils had multivariable adjusted incidence rate ratios of 1.98 (1.27-3.02) and 1.50 (0.99-2.27), respectively, compared to individuals with lower percentages of blood eosinophils (online supplementary figure $\mathrm{S} 4$ ).

Among individuals with COPD and $\mathrm{FEV}_{1}<50 \%$ pred, the multivariable adjusted hazard ratio (95\% CI) of all-cause mortality after hospitalisation due to pneumonia was 2.65 (1.08-6.52) comparing individuals with an eosinophil count of $\geqslant 0.34 \times 10^{9}$ cells $\cdot \mathrm{L}^{-1}$ to those $<0.34 \times 10^{9}$ cells. $\mathrm{L}^{-1}$ (online supplementary figure S5). Although the risk of all-cause mortality remained significant after additional adjustment for ICS, it was insignificant in the full model additionally adjusted for inflammatory biomarkers. 


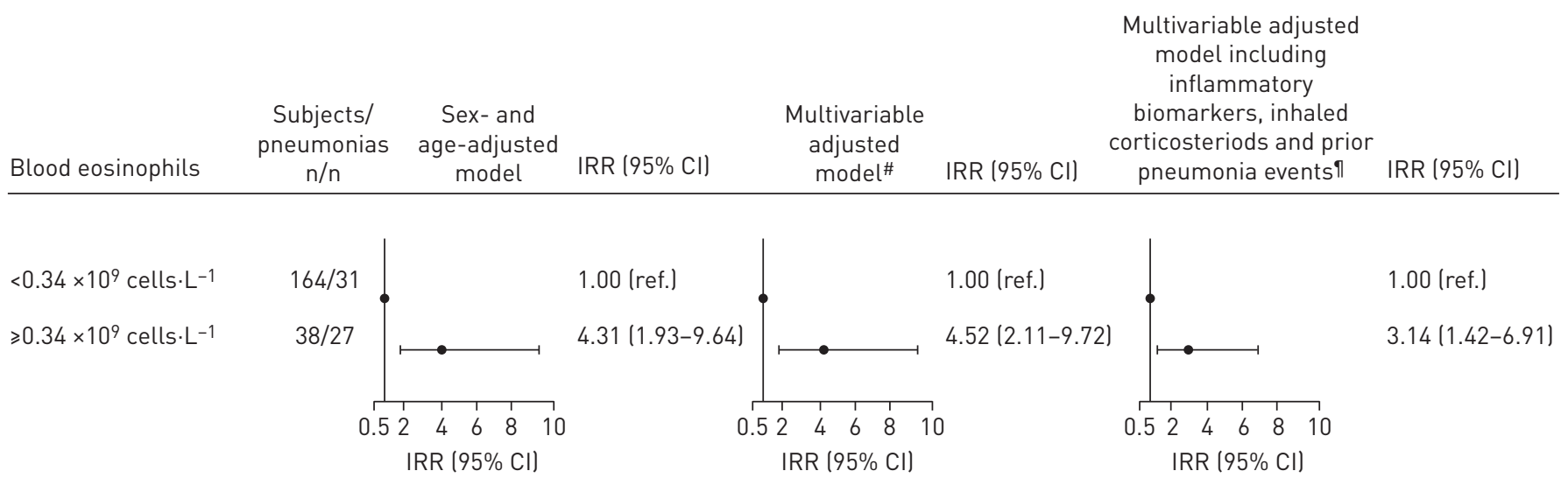

FIGURE 3 Risk of pneumonia in the clinical chronic obstructive pulmonary disease (COPD) population according to blood eosinophil count. Clinical COPD was defined as individuals with at least one exacerbation in the year prior to baseline, $\geqslant 10$ pack-years of smoking and forced expiratory volume in $1 \mathrm{~s}(\mathrm{FEV} 1)<70 \%$ predicted. IRR: incidence rate ratio. \#: adjusted for sex, age, smoking status, pack-years of smoking, body mass index, education and FEV1 \% pred; ๆ: inflammatory biomarkers were high sensitivity C-reactive protein, leukocyte count and fibrinogen.

Blood eosinophil counts and risk of pneumonia in individuals with clinical COPD

To further examine the risk of pneumonia among individuals with COPD, we used a previously defined subpopulation with clinical COPD based on recent exacerbation, $\geqslant 10$ pack-years and FEV1 $<70 \%$ pred. Among these individuals, we found a multivariable adjusted incidence rate ratio (95\% CI) of 4.52 (2.119.72) comparing individuals with a blood eosinophil count of $\geqslant 0.34 \times 10^{9}$ cells $\cdot \mathrm{L}^{-1}$ to those $<0.34 \times 10^{9}$ cells $\cdot \mathrm{L}^{-1}$ (figure 3). Further adjustments for inflammatory biomarkers, the use of ICS and prior pneumonia events resulted in a multivariable adjusted incidence rate ratio of 3.14 (1.46-6.72).

As for the total COPD population, using cut-points of $2 \%$ and $3.3 \%$ in blood eosinophils as percentages of total leukocytes gave similar results to those reported for the absolute count (online supplementary figure S6).

Use of ICS and risk of pneumonia stratified by blood eosinophil count

As previous studies have indicated a better response of ICS in COPD patients with higher blood eosinophil counts, and because the use ICS in COPD is also associated with an elevated risk of pneumonia, we investigated whether the risk of pneumonia in users of ICS differed according to blood eosinophil count. Among all individuals with COPD and FEV $1<50 \%$ pred, the use of ICS at baseline was associated with a higher risk of pneumonia with an incidence rate ratio of 1.62 (95\% CI 1.03-2.57) (figure 4). In analyses stratified by blood eosinophil count, the risk of pneumonia was elevated in users of ICS compared to nonusers in both strata, although this was not statistically significant in each stratum. There was no difference in risk of pneumonias according to the use of ICS in strata based on eosinophil count ( $p$-value for interaction 0.78).

In the subgroup with clinical COPD and less statistical power, the use of ICS was not significantly associated with a higher risk of pneumonias with an incidence rate ratio (95\% CI) of $1.72(0.81-3.67)$ comparing the use of ICS at baseline with no use. In stratified analyses, the risk of pneumonias was higher in individuals with a blood eosinophil count of $\geqslant 0.34 \times 10^{9}$ cells $\cdot \mathrm{L}^{-1}$ than in those with $<0.34 \times 10^{9}$ cells $\cdot \mathrm{L}^{-1}$; however, confidence intervals overlapped and there was no significant interaction of the use of ICS by blood eosinophil counts on risk of exacerbation ( $\mathrm{p}$-value for interaction=0.34).

\section{Repeated measurements of blood eosinophil counts}

For 890 individuals with COPD, we had repeated measurements of blood eosinophil counts measured with a median 10 years (IQR 8.5-10.6 years) apart (figure 5). Only 41 (6.4\% of the individuals included in the main analyses) of these had FEV $1<50 \%$ pred. In the COPD population with $\mathrm{FEV} 1<50 \%$ pred, $12 \%$ with eosinophil counts above the cut-point of $0.34 \times 10^{9}$ cells $\cdot \mathrm{L}^{-1}$ had lower values at second measurements, or vice versa. The corresponding percentage in the COPD population with $\mathrm{FEV}_{1} \geqslant 50 \%$ was $13 \%$.

\section{Discussion}

In this study of 7180 individuals with COPD from the general population, blood eosinophil count of $\geqslant 0.34 \times 10^{9}$ cells $\cdot \mathrm{L}^{-1}$ in individuals with $\mathrm{COPD}$ and $\mathrm{FEV} 1<50 \%$ pred was associated with a higher risk of future hospitalisations with pneumonia, compared with individuals with the same degree of airflow limitation but lower eosinophil count. However, the high risk was driven by few individuals in the whole COPD cohort. Only few studies have investigated the association between blood eosinophil count and risk 


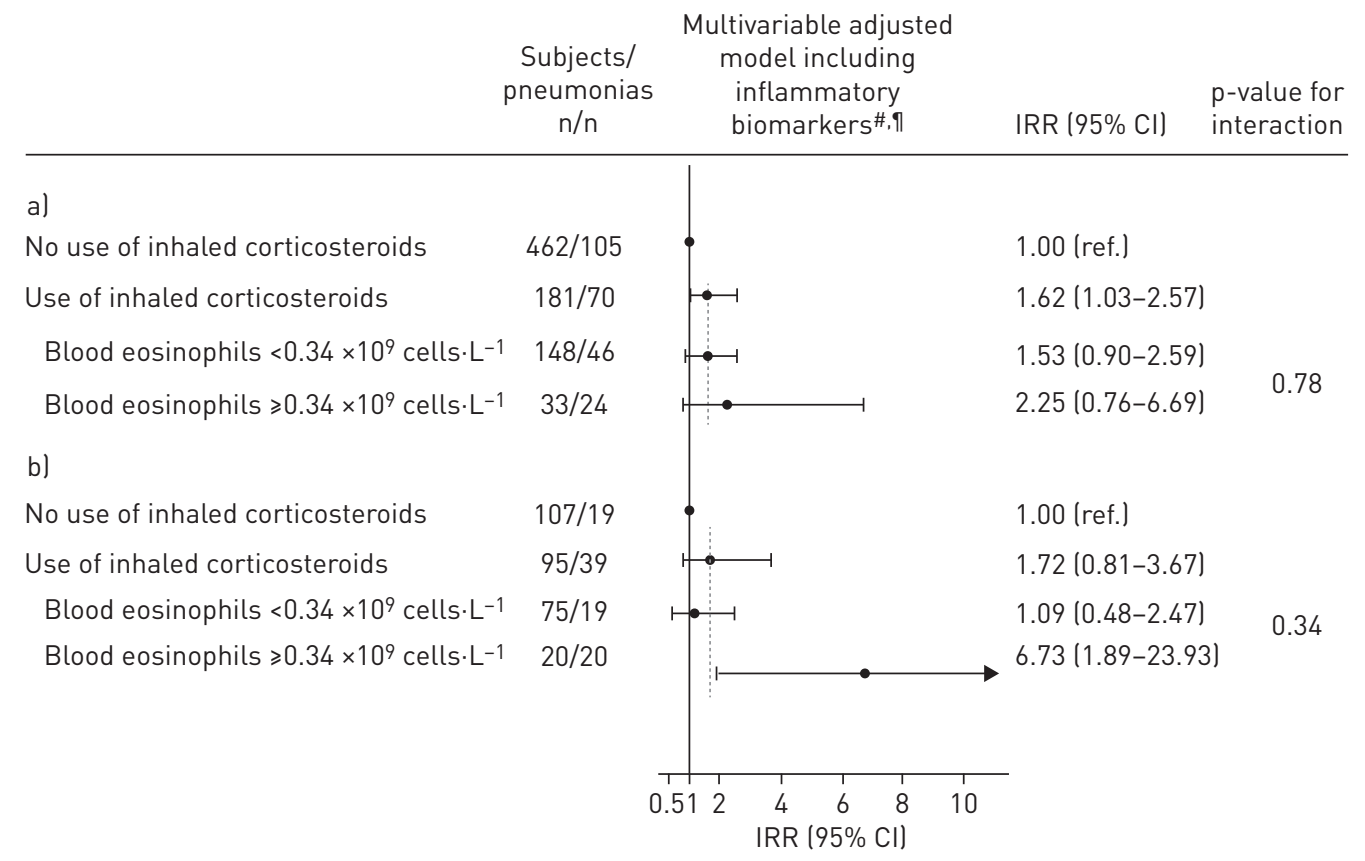

FIGURE 4 Risk of pneumonia according to the use of inhaled corticosteroids and blood eosinophil count. a) Risk of pneumonia comparing individuals using inhaled corticosteroids to individuals not using inhaled corticosteroids in the chronic obstructive pulmonary disease (COPD) population with forced expiratory volume in $1 \mathrm{~s}\left(\mathrm{FEV}_{1}\right)<50 \%$ predicted and risk of pneumonia associated with the use of inhaled corticosteroids stratified by levels of blood eosinophil count $<0.34 \times 10^{9}$ cells. $L^{-1}$ and $\geqslant 0.34 \times 10^{9}$ cells. $\left.L^{-1}(n=643) ; b\right)$ the same analyses for the clinical COPD population $(n=202)$. $p$-value for interaction was for use of inhaled corticosteroids by blood eosinophil counts on risk of exacerbation. IRR: incidence rate ratio. \#: adjusted for sex, age, smoking status, pack-years of smoking, body mass index, education and FEV $\%$ pred; " : inflammatory biomarkers were high sensitivity C-reactive protein, leukocyte count and fibrinogen.

of pneumonias, but knowledge of this relationship becomes relevant, as COPD patients with high blood eosinophil counts are candidates for ICS treatment, and as ICS as such elevate pneumonia risk in COPD. However, as we were only able to include pneumonias treated in a hospital setting, we cannot conclude on the association between blood eosinophil count and less severe pneumonias. Moreover, we cannot exclude that some severe exacerbations of COPD might have been misdiagnosed as pneumonia, which could potentially bias our results.

High blood eosinophil counts in COPD probably marks a phenotype with frequent exacerbations, although the underlying mechanism remains unknown. Eosinophilic activation during viral infections has been reported [22] and eosinophils might have an antibacterial role, although this is controversial and only
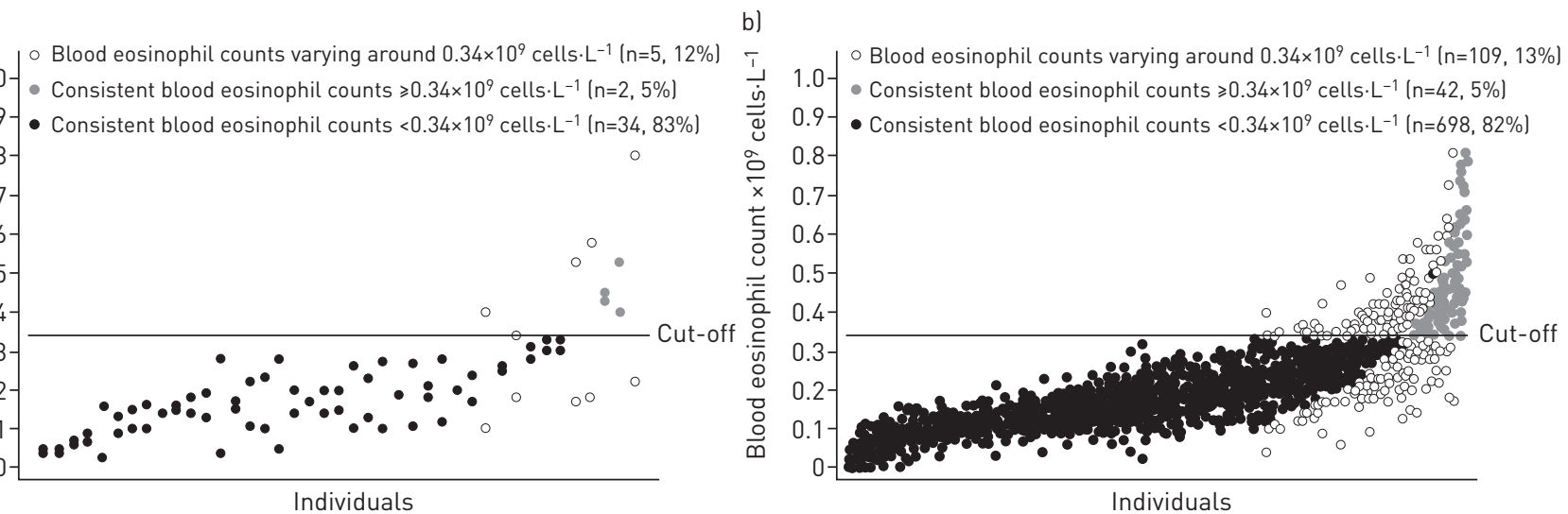

FIGURE 5 Repeated measurements of blood eosinophil counts 10 years apart in individuals with chronic obstructive pulmonary disease grouped according to forced expiratory volume in $1 \mathrm{~s}\left(\mathrm{FEV}_{1}\right) \%$ predicted. a) FEV $1<50 \%$ pred $(\mathrm{n}=41) ;$ b) $\mathrm{FEV} 1 \geqslant 50 \%$ pred ( $=849$ ). Each individual has two measurements, with each dot representing a single measurement. Cut-off value $0.34 \times 10^{9} \mathrm{cells} \cdot \mathrm{L}^{-1}$. 
reported in vitro [23]. The elevated sputum and blood eosinophil counts reported in both stable COPD $[12,24,25]$ and at exacerbations of the disease [11, 13] might reflect a persistent eosinophilic inflammation with high recruitment rate of eosinophils to the airways as part of chronic airway inflammation in individuals with severe lung function impairment and increased susceptibility to pneumonias. In our study, the high risk of pneumonias appeared not to be mediated through ICS use, prior exacerbations or prior repeated events of pneumonia, but rather related to the specific eosinophilic phenotype with severe lung impairment.

In contrast to high eosinophil counts, peripheral eosinopenia can be observed in response to acute inflammation or infection [26] and has previously been identified as a strong predictor of mortality in COPD patients hospitalised with acute exacerbations complicated by pneumonia [27]. However, in the general population, elevated blood eosinophil counts when the condition is stable have been associated with a higher risk of mortality from COPD in a study with up to 30 years of follow-up [28], although retrospective data from a cohort of COPD patients with shorter follow-up time did not support this [29]. Our group has previously shown that the increased COPD exacerbation frequency associated with a higher blood eosinophil count was more pronounced when restricted to severe exacerbations requiring hospitalisation [16]. In the present study, we found an association between a blood eosinophil count of $\geqslant 0.34 \times 10^{9}$ cells $\cdot \mathrm{L}^{-1}$ and high risk of pneumonias in individuals with COPD and severely impaired lung function, that is, a FEV $1<50 \%$ pred. Using cut-points of percentage of blood eosinophils, we found similar results. LANGE et al. [30], using data from another Copenhagen cohort, have previously shown that age and FEV1 \% pred are the most important risk factor for hospitalisation due to pneumonia in the general population. In the present study, we found no association between high blood eosinophil counts and pneumonia in individuals with COPD and less severe lung function impairment. We were able to demonstrate an association in a subgroup with clinical exacerbating COPD with low FEV1 and smoking history, similar to COPD patients included in clinical trials. However, our findings contrast with a recent post hoc meta-analysis of GlaxoSmithKline-funded clinical trials, including 10861 patients with COPD from 10 clinical trials, which reported a small increase in risk of pneumonias in patients with blood eosinophil counts $<2 \%$ [9]. The discrepancy may be due to different populations studied, as individuals with COPD identified from the general population, as in our study, might differ from patients included in clinical trials in terms of treatment. Another difference relates to the fact that our study had longer follow-up time than most clinical trials, which enabled us to capture more pneumonia events. The post hoc meta-analysis found no increased risk of pneumonia in COPD patients with blood eosinophil count $<2 \%$ in the trials of shorter duration, with less severe COPD patients, and with low incidence of pneumonia [9]. Previous post hoc analyses of randomised trials found no difference in pneumonia incidence according to subgroups divided by a blood eosinophil count of $2 \%[15,31]$ or the median blood eosinophil count [8]. However, the same analyses did find higher exacerbation rates with increasing levels of blood eosinophil counts and a better response to ICS among COPD patients with eosinophil counts $\geqslant 2 \%$, although recent data from the FLAME (Effect of Indacaterol Glycopyronium vs Fluticasone Salmeterol on COPD Exacerbations) study, a randomised trial of a combination of long-acting $\beta$-agonist and long-acting muscarinic antagonist compared with a combination of long-acting $\beta$-agonist and inhaled corticosteroid did not confirm blood eosinophils as a potential biomarker of ICS response [32]. In the present study, we found that use of ICS was associated with an elevated risk of pneumonia in individuals with COPD and severely impaired lung function. Although our data show a trend towards higher risk of pneumonias among individuals with high eosinophil count, this risk did not vary significantly according to blood eosinophil count, suggesting that the use of ICS among individuals with COPD and high blood eosinophil counts might not increase the risk of pneumonias further. This was true for individuals with clinical COPD and a history of exacerbations in which treatment with ICS is relevant. Although we used a cut-point in absolute blood eosinophil count, our findings are in accordance with the FLAME study, which reported a higher incidence of pneumonia in patients on ICS, regardless of their blood eosinophil count [33].

Strengths of the present study include the large sample size and the fact that we were able to follow all individuals through the Danish registries with no loss to follow-up. However, a limitation of this study is that we could only capture severe pneumonias treated in a hospital setting, as pneumonias treated in primary care by the general practitioners are not captured by the Danish registries [34]. Therefore, we cannot conclude on the association between blood eosinophil count and less severe pneumonia. Moreover, the present study included individuals with COPD from the general population, and thus the association between blood eosinophil count at stable state and risk of pneumonia may differ in a population of COPD patients recruited in a pulmonary department. As we rely on pneumonia diagnoses drawn from the national Danish Patient Registry we cannot exclude that some severe exacerbations of COPD may be reported as pneumonias instead, as the differential diagnosis between these two events can be difficult. In addition, we are limited by the lack of information on pneumococcal or influenza vaccination. 
Furthermore, it can be debated whether single measurements of blood eosinophil count during stable COPD can be used as a marker of eosinophilic airway inflammation [17, 35]. Yet, a study of 141 stable COPD patients found that a peripheral blood eosinophil count of $\geqslant 0.30 \times 10^{9}$ cells $\cdot \mathrm{L}^{-1}$ had a specificity of $76 \%$ and a sensitivity of $60 \%$ to identify sputum eosinophilia [12]. Data from the UK Clinical Practice Research Datalink have shown that blood eosinophil counts are more variable in COPD, especially for patients with higher baseline eosinophil levels [36]; however, this would tend to bias our result towards the null hypothesis. In our study we had repeated measurements of blood eosinophil counts in 890 individuals with COPD; of these, $13 \%$ had varying blood eosinophil counts around the cut-point of $0.34 \times 10^{9} \mathrm{cells} \cdot \mathrm{L}^{-1}$. Although repeated measurements were performed with a median of 10 years apart in only $6.5 \%$ of the individuals included in our main analyses, this suggests a certain stability of the blood eosinophil count in COPD. Lastly, as we defined COPD according to the lower limit of normal and ratio of FEV1/FVC based on spirometry measurements without the use of a bronchodilator we cannot exclude that some individuals had asthma and not COPD, although we excluded individuals with self-reported asthma from our definition of COPD. In our analyses, we adjusted for inflammation using established markers of low-grade inflammation such as C-reactive protein, fibrinogen and leukocytes. Adjustments for these confounders may be problematic as they may be intermediate variables or a descending proxy for an intermediate variable, and thus adjusting for these may bias results toward the null hypothesis [37], which might be the case with mortality after pneumonia.

In conclusion, in this population study of COPD defined as a ratio of FEV1/FVC under the lower limit of normal and below 0.7 determined without the use of a bronchodilator, we found that a blood eosinophil count of $\geqslant 0.34 \times 10^{9}$ cells $\mathrm{L}^{-1}$ in individuals with COPD and $\mathrm{FEV} 1<50 \%$ pred was associated with a higher risk of being hospitalised due to pneumonia. Among individuals with high blood eosinophil counts and FEV $1<50 \%$ pred, the use of ICS did not elevate the risk of pneumonia further. As we were not able to capture less-severe pneumonias, our study cannot conclude on the association between blood eosinophil count and pneumonias treated outside a hospital setting.

Acknowledgements: The authors would like to thank staff and participants of the Copenhagen General Population Study.

Conflict of interest: J. Vestbo has received personal fees from AstraZeneca, Boehringer Ingelheim, Chiesi Pharmaceuticals, GlaxoSmithKline and Novartis, outside the submitted work. P. Lange has received grants and personal fees from Almirall, AstraZeneca, Boehringer Ingelheim, Novartis and GlaxoSmithKline, and personal fees from Norpharma, Takeda and Pfizer, outside the submitted work.

Support statement: The study was funded by the Lundbeck Foundation, Denmark, and the Faculty of Health and Medical Sciences, University of Copenhagen, Denmark. The sponsors of the study had no role in study design, data collection, data analysis, data interpretation or writing of the paper. Funding information for this article has been deposited with the Crossref Funder Registry.

\section{References}

1 Almirall J, Bolíbar I, Serra-Prat M, et al. New evidence of risk factors for community-acquired pneumonia: a population-based study. Eur Respir J 2008; 31: 1274-1284.

2 Torres A, Blasi F, Dartois N, et al. Which individuals are at increased risk of pneumococcal disease and why? Impact of COPD, asthma, smoking, diabetes, and/or chronic heart disease on community-acquired pneumonia and invasive pneumococcal disease. Thorax 2015; 70: 984-989.

3 Müllerova H, Chigbo C, Hagan GW, et al. The natural history of community-acquired pneumonia in COPD patients: a population database analysis. Respir Med 2012; 106: 1124-1133.

4 Drummond MB, Dasenbrook EC, Pitz MW, et al. Inhaled corticosteroids in patients with stable chronic obstructive pulmonary disease: a systematic review and meta-analysis. JAMA 2008; 300: 2407-2416.

5 Crim C, Calverley PM, Anderson JA, et al. Pneumonia risk in COPD patients receiving inhaled corticosteroids alone or in combination: TORCH study results. Eur Respir J 2009; 34: 641-647.

6 Yang IA, Clarke MS, Sim EH, et al. Inhaled corticosteroids for stable chronic obstructive pulmonary disease. Cochrane Database Syst Rev 2012; 7: CD002991.

7 Dransfield MT, Bourbeau J, Jones PW, et al. Once-daily inhaled fluticasone furoate and vilanterol versus vilanterol only for prevention of exacerbations of COPD: two replicate double-blind, parallel-group, randomised controlled trials. Lancet Respir Med 2013; 1: 210-223.

8 Siddiqui SH, Guasconi A, Vestbo J, et al. Blood eosinophils: a biomarker of response to extrafine beclomethasone/ formoterol in chronic obstructive pulmonary disease. Am J Respir Crit Care Med 2015; 192: 523-525.

9 Pavord ID, Lettis S, Anzueto A, et al. Blood eosinophil count and pneumonia risk in patients with chronic obstructive pulmonary disease: a patient-level meta-analysis. Lancet Respir Med 2016; 4: 731-741.

10 Kolsum U, Donaldson GC, Singh R, et al. Blood and sputum eosinophils in COPD; relationship with bacterial load. Respir Res 2017; 18: 88.

11 Bafadhel M, McKenna S, Terry S, et al. Acute exacerbations of chronic obstructive pulmonary disease: identification of biologic clusters and their biomarkers. Am J Respir Crit Care Med 2011; 184: 662-671.

12 Negewo NA, McDonald VM, Baines KJ, et al. Peripheral blood eosinophils: a surrogate marker for airway eosinophilia in stable COPD. Int J Chron Obstruct Pulmon Dis 2016; 11: 1495-1504. 
13 Bafadhel M, Greening NJ, Harvey-Dunstan TC, et al. Blood eosinophils and outcomes in severe hospitalized exacerbations of COPD. Chest 2016; 150: 320-328.

14 Couillard S, Larivée P, Courteau J, et al. Eosinophils in COPD exacerbations are associated with increased readmissions. Chest 2017; 151: 366-373.

15 Pascoe S, Locantore N, Dransfield MT, et al. Blood eosinophil counts, exacerbations, and response to the addition of inhaled fluticasone furoate to vilanterol in patients with chronic obstructive pulmonary disease: a secondary analysis of data from two parallel randomised controlled trials. Lancet Respir Med 2015; 3: 435-442.

16 Vedel-Krogh S, Nielsen SF, Lange P, et al. Blood eosinophils and exacerbations in chronic obstructive pulmonary disease. The Copenhagen General Population Study. Am J Respir Crit Care Med 2016; 193: 965-974.

17 Casanova C, Celli BR, de-Torres JP, et al. Prevalence of persistent blood eosinophilia: relation to outcomes in patients with COPD. Eur Respir J 2017; 50: 1701162

18 Thomsen M, Ingebrigtsen TS, Marott JL, et al. Inflammatory biomarkers and exacerbations in chronic obstructive pulmonary disease. JAMA 2013; 309: 2353-2361.

19 Çolak Y, Afzal S, Nordestgaard BG, et al. Characteristics and prognosis of never-smokers and smokers with asthma in the Copenhagen General Population Study. A prospective cohort study. Am J Respir Crit Care Med 2015; 192: 172-181

20 Vedel-Krogh S, Fallgaard Neilsen S, Lange P, et al. Association of blood eosinophil and blood neutrophil counts with asthma exacerbations in the Copenhagen General Population Study. Clin Chem 2017; 63: 823-832.

21 Thomsen $\mathrm{M}$, Dahl M, Lange $\mathrm{P}$, et al. Inflammatory biomarkers and comorbidities in chronic obstructive pulmonary disease. Am J Respir Crit Care Med 2012; 186: 982-988.

22 Kristjansson S, Bjarnarson SP, Wennergren G, et al. Respiratory syncytial virus and other respiratory viruses during the first 3 months of life promote a local TH2-like response. J Allergy Clin Immunol 2005; 116: 805-811.

23 Torrent M, Navarro S, Moussaoui M, et al. Eosinophil cationic protein high-affinity binding to bacteria-wall lipopolysaccharides and peptidoglycans. Biochemistry 2008; 47: 3544-3555.

24 Leigh R, Pizzichini MM, Morris MM, et al. Stable COPD: predicting benefit from high-dose inhaled corticosteroid treatment. Eur Respir J 2006; 27: 964-971.

25 Singh D, Kolsum U, Brightling CE, et al. Eosinophilic inflammation in COPD: prevalence and clinical characteristics. Eur Respir J 2014; 44: 1697-1700.

26 Bass DA, Gonwa TA, Szejda P, et al. Eosinopenia of acute infection: production of eosinopenia by chemotactic factors of acute inflammation. J Clin Invest 1980; 65: 1265-1271.

27 Steer J, Gibson J, Bourke SC. The DECAF Score: predicting hospital mortality in exacerbations of chronic obstructive pulmonary disease. Thorax 2012; 67: 970-976.

28 Hospers JJ, Schouten JP, Weiss ST, et al. Asthma attacks with eosinophilia predict mortality from chronic obstructive pulmonary disease in a general population sample. Am J Respir Crit Care Med 1999; 160: 1869-1874.

29 Duman D, Aksoy E, Agca MC, et al. The utility of inflammatory markers to predict readmissions and mortality in COPD cases with or without eosinophilia. Int J Chron Obstruct Pulmon Dis 2015; 10: 2469-2478.

30 Lange P, Vestbo J, Nyboe J. Risk factors for death and hospitalization from pneumonia. A prospective study of a general population. Eur Respir J 1995; 8: 1694-1698.

31 Pavord ID, Lettis S, Locantore N, et al. Blood eosinophils and inhaled corticosteroid/long-acting $\beta$-2 agonist efficacy in COPD. Thorax 2016; 71: 118-125.

32 Roche N, Chapman KR, Vogelmeier CF, et al. Blood eosinophils and response to maintenance chronic obstructive pulmonary disease treatment: data from the FLAME trial. Am J Respir Crit Care Med 2017; 195: 1189-1197.

33 Wedzicha JA, Banerji D, Chapman KR, et al. Indacaterol-glycopyrronium versus salmeterol-fluticasone for COPD. N Engl J Med 2016; 374: 2222-2234.

34 Eccles S, Pincus C, Higgins B, et al. Diagnosis and management of community and hospital acquired pneumonia in adults: summary of NICE guidance. BMJ 2014; 349: g6722.

35 Turato G, Semenzato U, Bazzan E, et al. Blood eosinophilia neither reflects tissue eosinophils nor worsens clinical outcomes in chronic obstructive pulmonary disease. Am J Respir Crit Care Med 2018; 197: 1216-1219.

36 Oshagbemi OA, Burden AM, Braeken DCW, et al. Stability of blood eosinophils in patients with chronic obstructive pulmonary disease and in control subjects, and the impact of sex, age, smoking, and baseline counts. Am J Respir Crit Care Med 2017; 195: 1402-1404.

37 Schisterman EF, Cole SR, Platt RW. Overadjustment bias and unnecessary adjustment in epidemiologic studies. Epidemiology 2009; 20: 488-495. 